\title{
Association between RNF2+P-AKT expression in pretreatment biopsy specimens, and poor survival following radiotherapy in patients with esophageal squamous cell carcinoma
}

\author{
QIAOFANG LI ${ }^{1,2}$, SHUGUANG LI ${ }^{1}$, XINGXIAO YANG ${ }^{3}$, XUEYUAN ZHANG ${ }^{1}$, \\ CHUNYANG SONG ${ }^{1}$ and SHUCHAI ZHU ${ }^{1}$
}

\author{
${ }^{1}$ Department of Radiation Oncology, The Fourth Hospital of Hebei Medical University, Shijiazhuang, \\ Hebei 050011; ${ }^{2}$ Department of Oncology, Hebei General Hospital, Shijiazhuang, Hebei 050051; \\ ${ }^{3}$ Department of Infectious Disease, The Fourth Hospital of Hebei Medical University, \\ Shijiazhuang, Hebei 050011, P.R. China
}

Received December 15, 2018; Accepted July 9, 2019

DOI: $10.3892 / 01.2019 .10727$

\begin{abstract}
The protein expression levels of Ring finger protein 2 (RNF2) and phosphor-protein kinase B (P-AKT) were determined in esophageal squamous cell carcinoma (ESCC) tissues, and the association between patient clinicopathological characteristics and survival time following definitive intensity-modulated radiotherapy was assessed. Cancerous biopsy tissues were collected from patients with ESCC at The Fourth Affiliated Hospital of Hebei Medical University between January 2010 and December 2013. Of these 99 cases, 83 were used to analyze the protein expression level of RNF2 (89.2\% positive), 85 for P-AKT (65.9\% positive) and 80 for RNF2+P-AKT protein expression levels ( $62.5 \%$ both positive). The expression levels of RNF2 protein in ESCC were associated with tumor volume $(\mathrm{P}=0.024)$, whilst those of $\mathrm{P}-\mathrm{AKT}$ and RNF2+PAKT were associated with sex $(\mathrm{P}=0.041$ and $\mathrm{P}=0.003$, respectively). There were no significant differences in overall survival (OS) or progression-free survival (PFS) rate between the RNF2 ${ }^{-}$and the $\mathrm{RNF}^{+++++}$groups $(\mathrm{P}=0.134$ and $\mathrm{P}=0.366$, respectively), or between the $\mathrm{P}-\mathrm{AKT}$ group and $\mathrm{P}-\mathrm{AKT}^{+++++}$ group $(\mathrm{P}=0.468 ; \mathrm{P}=0.580$, respectively). The 1-, 3 - and 5-year OS rates were $68.0,28.0$, and $20.0 \%$, and $86.7,53.3$, and $31.1 \%$, in the RNF2/P-AKT ${ }^{+}$group and Other group, respectively $\left(\chi^{2}=4.205 ; \mathrm{P}=0.040\right)$. Multivariate analysis revealed that age, $\mathrm{T}$ stage and RNF2+P-AKT expression were independent prognostic factors for $\mathrm{ESCC}(\mathrm{P}=0.010, \mathrm{P}=0.008$ and $\mathrm{P}=0.010$, respectively). The expression of RNF2+P-AKT combined was an independent prognostic factor affecting survival rate, and
\end{abstract}

Correspondence to: Professor Shuchai Zhu, Department of Radiation Oncology, The Fourth Hospital of Hebei Medical University, 12 Jiankang Road, Shijiazhuang, Hebei 050011, P.R. China E-mail: lqf20006@126.com

Key words: esophageal cancer, radiotherapy, Ring finger protein 2, phospho-protein kinase B, survival, prognostic factors therefore presents a potential prognostic indicator for patients with ESCC, treated with definitive radiotherapy.

\section{Introduction}

Esophageal cancer is a common malignancy of the digestive tract and the sixth for cancer death worldwide (1). The predominant histopathological types are squamous cell carcinoma and adenocarcinoma, and in China, squamous cell carcinoma is most frequently exhibited (2). Although there are numerous treatments available for esophageal cancer, the 5-year survival rate remains at $\sim 20 \%$ (3). The discovery of improved predictive markers, early detection and improved treatment options are key to increasing the overall survival (OS) time of patients with esophageal cancer.

There are $\geq 2$ types of nuclear protein complex in the polycomb group family, namely polycomb-repressive complex 1 (PRC1) and PRC2 (4). Human PRC1 includes polycomb (PC), polyhomeotic $(\mathrm{PH}), \mathrm{B}$-cell-specific Moloney murine leukemia virus integration site-1 (BMI1), RING1a and RING1b (5). PRC2 includes embryonic ectoderm development (EED), enhancer of zeste homolog 2 (EZH2) and suppressor of zeste 12 homolog (SUZ12) (6). In the PRC1 complex, BMI1 and RNF2 heterodimers form E3 ubiquitin ligase in the $\mathrm{N}$-terminal area of the RING (7-9). BMI1 expression is upregulated in hepatocellular carcinoma (10) and pancreatic cancer (11), and RNF2 is overexpressed in many different types of tumors, such as gastrointestinal tumors, lymphomas (12), breast cancer (13), ovarian tumor tissues (14). A previous biological study revealed that silencing Ring finger protein 2 (RNF2) in esophageal cancer cells may lead to defects in DNA damage pathways, and therefore increase sensitivity to radiotherapy (15). Another previous study demonstrated that a high expression level of BMI1 promoted the expression of phosphor-protein kinase B (P-AKT) following radiotherapy, and that the phosphoinositide 3-kinase (PI3K)/AKT pathway was involved in resistance to radiotherapy (16). However, the potential association between P-AKT and the RNF2 expression level, and the survival of patients with esophageal squamous cell carcinoma (ESCC) treated with radiotherapy, requires further investigation. 
Therefore, in the present study, it was hypothesized that an increased expression of RNF2 and P-AKT may result in increased resistance to radiotherapy in patients with ESCC. Immunohistochemistry was used to detect RNF2 and P-AKT protein expression in patients prior to radiotherapy, and the association between RNF2+P-AKT protein expression and clinicopathological features and survival prognosis was retrospectively analyzed, in order to investigate the role of RNF2+P-AKT protein expression in patients with ESCC following radiotherapy.

\section{Patients and methods}

Patient sample selection. Between January 2010 and December 2013, 99 I-IVa (American Joint Committee on Cancer, 2010) (17) stage ESCC patients, with a mean age of 66 years (range, $48-87$ ) and a male:female ratio of $1.61(61 / 38)$, were selected from The Fourth Affiliated Hospital of Hebei Medical University, and their tumor samples (formalin-fixed and paraffin-embedded) were taken for the analysis of RNF2 and P-AKT.Patients who had received any anti-cancer treatment prior to diagnosis were excluded. The inclusion criteria were as follows: i) Histological evidence of invasive squamous-cell carcinoma of the esophagus; and ii) informed written consent to receive radiotherapy (RT). Detailed clinical and follow-up data was obtained from all patients, and written consent was obtained for the collection of tissue specimens. The study protocols were approved by the Ethics Committee for Clinical Research of the Fourth Affiliated Medical University.

Immunohistochemistry (IHC). IHC was performed using conventional methods. Briefly, paraffin-embedded ESCC tissues were sliced into 4- $\mu \mathrm{m}$-thick sections, deparaffinized in xylene at $55^{\circ} \mathrm{C}$, and rehydrated in a descending alcohol series $(100 \%$ alcohol first time, $100 \%$ alcohol second time, $95 \%$ alcohol, $80 \%$ alcohol) for $10 \mathrm{~min}$ respectively. Endogenous peroxidases were blocked using $3 \%$ hydrogen peroxide for $20 \mathrm{~min}$ at $37^{\circ} \mathrm{C}$, and antigen retrieval was conducted using citrate buffer (Thermo Fisher Scientific, Inc.) in a microwave oven for $15 \mathrm{~min}$ at $98^{\circ} \mathrm{C}$. The sections were incubated with primary antibodies against RNF2 (1:100; cat. no. ab101273; Abcam) and P-AKT (1:40; cat. no. ab81283; Abcam) at $4^{\circ} \mathrm{C}$ overnight, followed by subsequent incubation with horseradish peroxidase-conjugated goat anti-rabbit polyclonal antibody (1:100; cat. no. SP-9000; Beijing Zhongshan Golden Bridge Biotechnology Co., Ltd.) for $30 \mathrm{~min}$ at $37^{\circ} \mathrm{C}$. The sections were then processed with 3,3'-diaminobenzidine (DAB) for $5 \mathrm{~min}$ at $37^{\circ} \mathrm{C}$ and counterstained with hematoxylin for $16 \mathrm{~min}$ at $37^{\circ} \mathrm{C}$ and assessed under a light microscope (Olympus Corporation) by two pathologists who were blinded to the clinical parameters of the patients.

Reactivity scoring and interpretation of IHC. The expression of RNF2 and P-AKT was microscopically observed using a light microscope, and this was identified to be predominantly located in the nucleus. The IHC results were independently evaluated by 2 pathologists with no prior knowledge of the patients' clinicopathological data. If different scores were assigned for the same sample, the sample was revaluated and, if required, further discussed to determine a final score. For positive staining in the nuclei, the most intensively stained region was initially selected with a low-power magnification (x100). The percentage of positively stained cells was then calculated from the observation of 5 random sections at a higher magnification (x200). A total of 100 tumor cells were counted in each section, and the number and intensity classification of the positively-stained cells was determined. The immunoreactive score (IRS) system was used. The staining intensity classification $(18,19)$ was as follows: i) 0 , unstained; ii) 1, light yellow; iii) 2, brownish yellow; and iv) 3 , tan. The percentage score for positive cells was classified as follows: i) 0 , positive cells $\leq 5 \%$; ii) 1 , positive cells $6-25 \%$; iii) 2 , positive cells $26-50 \%$; iv) 3 , positive cells $51-75 \%$; and v) 4 , positive cells $>75 \%$. The total sum of the staining intensity and percentage-positive scores was indicated as follows: i) $0-1$, negative (-); ii) 2-3, weakly positive $\left({ }^{+}\right)$; iii) $4-5$, moderately positive $\left({ }^{++}\right)$; and iv) $6-7$, strongly positive $\left(^{+++}\right)$. Where the degree of positive staining is not being addressed, the word 'positive' has been used to indicate positive staining in general, in place of the percentage-positive scoring symbols, which is also suitable for the negative staining.

Statistical analysis. SPSS 19.0 statistical software (IBM Corp.) was used for all statistical analyses. The relationship between RNF2, P-AKT and patient clinicopathological parameters was analyzed using the $\chi^{2}$ test, extended Fisher's exact test, linear-by-linear association and the Goodman-Kruskal $\gamma$ test. The Kaplan-Meier method was used to analyze survival prognosis, in addition to the log-rank test. Univariate and multivariate analysis of survival prognosis was performed using cox regression analysis. $\mathrm{P}<0.05$ was considered to indicate a statistically significant difference.

\section{Results}

Clinical data and characteristics. IHC analysis was performed on 99 patients with ESCC, pathologically diagnosed at The Fourth Affiliated Hospital of Hebei Medical University. Due to incomplete clinicopathological or IHC data, or discontinued radiotherapy, a number of patients were excluded from the study. As a result, a total of 83 patients were assigned to the RNF2 group, 85 to the P-AKT group, and 80 to the RNF2+P-AKT group. Detailed clinical data are outlined in Table I.

Influence of RNF2 protein expression level on ESCC. IHC analysis of patients' specimens revealed that the expression of RNF2 protein was primarily localized to the nuclei of tumor cells (Fig. 1). Among the 83 cases of ESCC, 9 (10.8\%) were RNF2-negative, while $74(89.2 \%)$ exhibited positive expression levels of RNF2; of these RNF2-positive patients, $20(24.1 \%), 18(21.7 \%)$ and $36(43.4 \%)$ demonstrated weak, moderate and strong-positive expression levels, respectively. Furthermore, there was a significant association between RNF2 expression and tumor volume $(\mathrm{P}<0.05)$, whereas no significant association was revealed for any other clinicopathological feature, including age, sex, tumor site, tumor length and Tumor-Node-Metastasis (TNM) stage (17) (Table II). 
Table I. Demographic, baseline variables and treatment characteristics of the study population.

\begin{tabular}{|c|c|c|c|}
\hline Variables & RNF2 (n=83) (\%) & $\mathrm{P}-\mathrm{AKT}(\mathrm{n}=85)(\%)$ & $\mathrm{RNF} 2 / \mathrm{P}-\mathrm{AKT}(\mathrm{n}=80)(\%)$ \\
\hline \multicolumn{4}{|l|}{ Sex } \\
\hline Male & $51(61.4)$ & $53(62.4)$ & $49(61.2)$ \\
\hline Female & $32(38.6)$ & $32(37.6)$ & $31(38.8)$ \\
\hline \multicolumn{4}{|l|}{ Age (years) } \\
\hline$\leq 66$ & $44(53.0)$ & $45(52.9)$ & $43(53.8)$ \\
\hline$>66$ & $39(47.0)$ & $40(47.1)$ & $37(46.3)$ \\
\hline \multicolumn{4}{|l|}{ Tumor location } \\
\hline Cervical & $6 \quad(7.2)$ & $6(7.1)$ & $6(7.5)$ \\
\hline Upper thoracic & $24(28.9)$ & $25(29.4)$ & $24(30.0)$ \\
\hline Middle thoracic & $37(44.6)$ & $38(44.7)$ & $34(42.5)$ \\
\hline Lower thoracic & $16(19.3)$ & $16(18.8)$ & $16(20.0)$ \\
\hline \multicolumn{4}{|l|}{ Tumor length $(\mathrm{cm})$} \\
\hline$\leq 3$ & $4 \quad(4.8)$ & $4 \quad(4.7)$ & $4(5.0)$ \\
\hline $3-5$ & $33(39.8)$ & $33(38.8)$ & $32(40.0)$ \\
\hline $5-7$ & $24(28.9)$ & $25(29.4)$ & $23(28.8)$ \\
\hline$>7$ & $22(26.5)$ & $23(27.1)$ & $21(26.3)$ \\
\hline \multicolumn{4}{|c|}{ Tumor volume $\left(\mathrm{cm}^{3}\right)$} \\
\hline$\leq 25$ & $25(30.1)$ & $26(30.6)$ & $24(30.0)$ \\
\hline$>25$ & $58(69.9)$ & $59(69.4)$ & $56(70.0)$ \\
\hline \multicolumn{4}{|l|}{ T stage } \\
\hline $1+2$ & $29(34.9)$ & $29(34.1)$ & $27(33.8)$ \\
\hline $3+4$ & $54(65.1)$ & $56(65.9)$ & $53(66.3)$ \\
\hline \multicolumn{4}{|l|}{$\mathrm{N}$ stage } \\
\hline 0 & $34(41.0)$ & $35(41.2)$ & $33(41.3)$ \\
\hline+ & $49(59.0)$ & $50(58.8)$ & $47(58.8)$ \\
\hline \multicolumn{4}{|l|}{ Tumor- } \\
\hline \multicolumn{4}{|c|}{ Node-Metastasis stage (17) } \\
\hline $\mathrm{I}+\mathrm{II}$ & $36(43.4)$ & $37(43.5)$ & $34(42.5)$ \\
\hline III+IV & $47(56.6)$ & $48(56.5)$ & $46(57.5)$ \\
\hline \multicolumn{4}{|l|}{ Radiation field } \\
\hline IFI & $45(54.2)$ & $46(54.1)$ & $43(53.8)$ \\
\hline ENI & $38(45.8)$ & $39(45.9)$ & $37(46.3)$ \\
\hline \multicolumn{4}{|c|}{ Radiation dose (Gy) } \\
\hline$\leq 60$ & $42(50.6)$ & $43(50.6)$ & $40(50.0)$ \\
\hline$>60$ & $41(49.4)$ & $42(49.4)$ & $40(50.0)$ \\
\hline \multicolumn{4}{|l|}{ Chemotherapy } \\
\hline No & $41(49.4)$ & $43(50.6)$ & $38(47.5)$ \\
\hline Yes & $42(50.6)$ & $42(49.4)$ & $42(52.5)$ \\
\hline
\end{tabular}

RNF2, Ring finger protein 2; P-AKT, phosphor-protein kinase B; IFI, involved field radiation; ENI, elective nodal irradiation.

Influence of P-AKT protein expression on ESCC. The assessment of the P-AKT expression level was determined for 85 tumor samples, and this was identified to be predominantly present in the nuclei of tumor cells (Fig. 2). A total of $29(34.1 \%)$ patient samples were classified as expression-negative, whereas $56(65.9 \%)$ exhibited positive P-AKT expression. In the P-AKT-positive group, 39 (45.9\%), 16 (18.8\%) and $1(1.2 \%)$ samples exhibited weak, moderate and strong-positive expression levels, respectively.
There was also a significant association between P-AKT expression and the sex of the patient $(\mathrm{P}<0.05)$, whereas no such association was observed for the other clinicopathological features, including age, tumor site, tumor length and volume, T, $\mathrm{N}$ and TNM stage (Table III).

Influence ofRNF $2+P-A K T$ proteinexpressiononESCC.Among the 80 samples used to assess the level of RNF2+P-AKT expression, 5 patients $(6.25 \%)$ were RNF2-negative/P-AKT-negative, 
Table II. Association between RNF2 expression and the clinicopathological variables of patients with esophageal squamous cell carcinoma.

\begin{tabular}{|c|c|c|c|c|c|c|c|c|c|}
\hline \multirow[b]{2}{*}{ Variables } & \multicolumn{8}{|c|}{ RNF2 expression } & \multirow[b]{2}{*}{ P-value } \\
\hline & $\begin{array}{c}(-) \\
(n=9)\end{array}$ & $\%$ & $\begin{array}{c}(+) \\
(n=20)\end{array}$ & $\%$ & $\begin{array}{c}(++) \\
(n=18)\end{array}$ & $\%$ & $\begin{array}{l}(+++) \\
(n=36)\end{array}$ & $\%$ & \\
\hline \multicolumn{10}{|l|}{ Sex } \\
\hline Male & 4 & 44.4 & 12 & 60.0 & 14 & 77.8 & 21 & 58.3 & \multirow[t]{2}{*}{0.635} \\
\hline Female & 5 & 55.6 & 8 & 40.0 & 4 & 22.2 & 15 & 41.7 & \\
\hline \multicolumn{10}{|l|}{ Age, years } \\
\hline$\leq 66$ & 6 & 66.7 & 13 & 65.0 & 7 & 38.9 & 18 & 50.0 & \multirow[t]{2}{*}{0.254} \\
\hline$>66$ & 3 & 33.3 & 7 & 35.0 & 11 & 61.1 & 18 & 50.0 & \\
\hline \multicolumn{10}{|l|}{ Tumor location } \\
\hline Cervical & 1 & 11.1 & 2 & 10.0 & 2 & 11.1 & 1 & 2.8 & \multirow[t]{4}{*}{0.579} \\
\hline Upper thoracic & 2 & 22.2 & 6 & 30.0 & 5 & 27.8 & 11 & 30.6 & \\
\hline Middle thoracic & 4 & 44.4 & 8 & 40.0 & 9 & 50.0 & 16 & 44.4 & \\
\hline Lower thoracic & 2 & 22.2 & 4 & 20.0 & 2 & 11.1 & 8 & 22.2 & \\
\hline \multicolumn{10}{|l|}{ Tumor length, cm } \\
\hline$\leq 5$ & 6 & 66.7 & 7 & 35.0 & 11 & 61.1 & 13 & 36.1 & \multirow[t]{2}{*}{0.269} \\
\hline$>5$ & 3 & 33.3 & 13 & 65.0 & 7 & 38.9 & 23 & 63.9 & \\
\hline \multicolumn{10}{|c|}{ Tumor volume, $\mathrm{cm}^{3}$} \\
\hline$\leq 25$ & 5 & 55.6 & 6 & 30.0 & 8 & 44.4 & 6 & 16.7 & \multirow[t]{2}{*}{0.024} \\
\hline$>25$ & 4 & 44.4 & 14 & 70.0 & 10 & 55.6 & 30 & 83.3 & \\
\hline \multicolumn{10}{|l|}{ T stage } \\
\hline $1+2$ & 4 & 44.4 & 7 & 35.0 & 7 & 38.9 & 11 & 30.6 & \multirow[t]{2}{*}{0.467} \\
\hline $3+4$ & 5 & 55.6 & 13 & 65.0 & 11 & 61.1 & 25 & 69.4 & \\
\hline \multicolumn{10}{|l|}{$\mathrm{N}$ stage } \\
\hline 0 & 4 & 44.4 & 8 & 40.0 & 10 & 55.6 & 12 & 33.3 & \multirow[t]{2}{*}{0.503} \\
\hline+ & 5 & 55.6 & 12 & 60.0 & 8 & 44.4 & 24 & 66.7 & \\
\hline \multicolumn{10}{|c|}{$\begin{array}{l}\text { Tumor-Node- } \\
\text { Metastasis stage (17) }\end{array}$} \\
\hline $\mathrm{I}+\mathrm{II}$ & 4 & 44.4 & 9 & 45.0 & 7 & 38.9 & 16 & 44.4 & \multirow[t]{2}{*}{0.992} \\
\hline III+IV & 5 & 55.6 & 11 & 55.0 & 11 & 61.1 & 20 & 55.6 & \\
\hline
\end{tabular}

RNF2, Ring finger protein 2.

$21(26.25 \%)$ were RNF2-positive/P-AKT-negative, 4 (5.00\%) were RNF2-negative/P-AKT-positive, and 50 patients $(62.50 \%)$ were RNF2-positive/P-AKT-positive. Furthermore, there was a significant association between RNF2-positive/ P-AKT-positive expression and sex $\left(\chi^{2}=9.132 ; \mathrm{P}=0.003\right)$, and an association with $\mathrm{T}$ stage $\left(\chi^{2}=7.240 ; \mathrm{P}=0.065\right)$, yet no significant association with age, tumor length, $\mathrm{N}$ stage or TNM stage (Table IV).

Association between RNF2 and P-AKT protein expression level and $O S$. The patient follow-up date was December 2016, with a median follow-up time of 80.78 months (95\% CI, 61.06-80.61 months) and a loss rate of $4.0 \%$ (4/99) due to loss of contact. Kaplan-Meier survival curves were generated to estimate the survival rates of these patients. The results revealed no significant differences in OS and progression-free survival (PFS) rates between the
RNF2 ${ }^{-}$and $\mathrm{RNF}^{+-+++}$groups $\left(\chi^{2}=2.244, \mathrm{P}=0.134 ; \chi^{2}=0.818\right.$, $\mathrm{P}=0.366)$, or between the $\mathrm{P}-\mathrm{AKT}^{-}$and $\mathrm{P}-\mathrm{AKT}^{+-++}$groups $\left(\chi^{2}=0.526, P=0.468 ; \chi^{2}=0.306, P=0.580 ;\right.$ Fig. $3 A$ and $B$; Table V).

Furthermore, the results illustrated a median survival time of 15.7 and 36.0 months; the 1,3 and 5-year survival rates were 68.0, 28.0 and $20.0 \%$, and 86.7, 53.3 and $31.1 \%\left(\chi^{2}=4.205\right.$; $\mathrm{P}=0.040)$ in the RNF2+P-AKT-positive expression group and the Other group, respectively (Fig. 4). PFS was not significantly different between the RNF2+P-AKT-positive expression and Other group $\left(\chi^{2}=3.407 ; \mathrm{P}=0.065\right.$; Table $\left.\mathrm{V}\right)$.

Univariate analysis showed that age, $\mathrm{T}$ stage, tumor volume, RNF2 protein expression, P-AKT protein expression and RNF2+P-AKT expression were prognostic factors affecting $\mathrm{OS}(\mathrm{P}=0.036,0.023,0.039,0.007,0.003$ and 0.040 , respectively). Furthermore, multivariate analysis demonstrated that age, $\mathrm{T}$ stage and RNF2+P-AKT expression were 
A

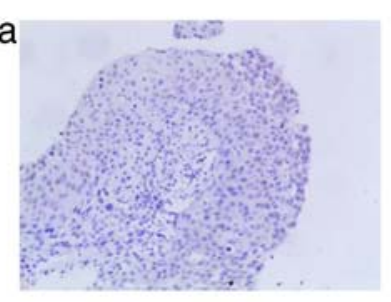

$\mathrm{B}_{\mathrm{a}}$

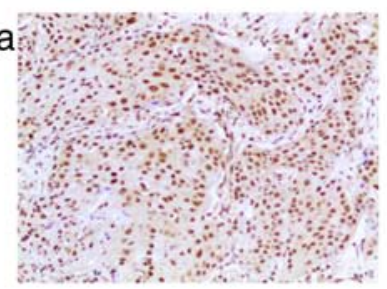

$\mathrm{C}_{\mathrm{a}}$

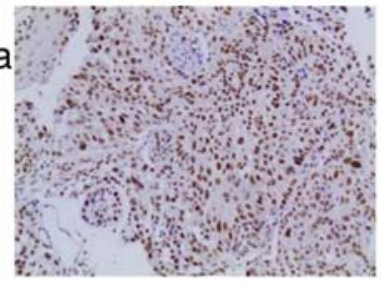

$\mathrm{D}_{\mathrm{a}}$

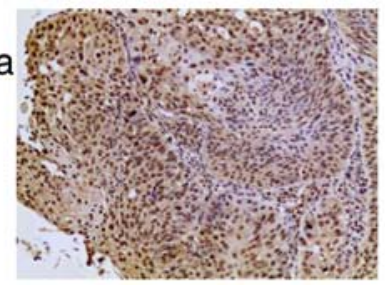

b

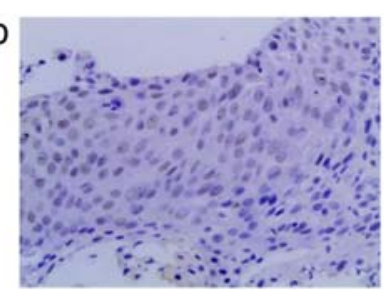

b

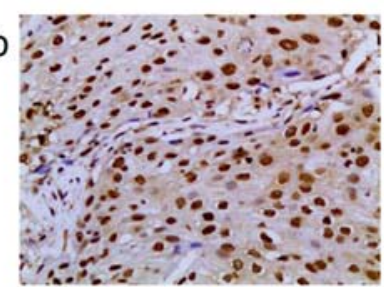

$\mathrm{b}$
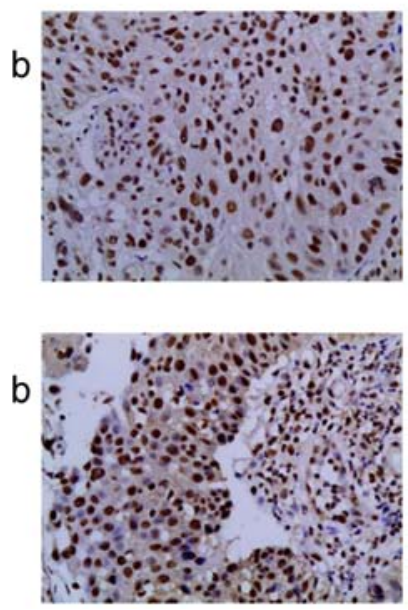

Figure 1. Expression levels of RNF2 protein in ESCC tissues. (A) No RNF2 expression in ESCC tissues; (a) magnification, $x 100$ and (b) magnification, x200. (B) Weak expression of RNF2 in ESCC tissues; (a) magnification, x100 and (b) magnification, x200. (C) Moderate expression of RNF2 in ESCC tissues; (a) magnification, x100 and (b) magnification, x200. (D) Strong expression of RNF2 in ESCC tissues; (a) magnification, x100 and (b) magnification, $\mathrm{x} 200 . \mathrm{RNF} 2$, Ring finger protein 2; ESCC, esophageal squamous cell carcinoma.

independent prognostic factors for $\operatorname{ESCC}(\mathrm{P}=0.010,0.008$ and 0.010 , respectively; Table VI).

\section{Discussion}

In the present study, IHC analysis was performed on the pathological tissues of patients with ESCC, which revealed that RNF2 and P-AKT protein expression levels were high in ESCC tissues. Furthermore, patient survival rates in the RNF2+P-AKT-positive expression group were lower compared with that in the other group, suggesting that the expression of RNF2+P-AKT in patients with ESCC who had previously received radiotherapy was associated with poor prognosis.

The overexpression of RNF2 has been reported in numerous types of solid tumor, such as gastrointestinal tumors, lymphomas (12), breast cancer (13) and ovarian tumor tissues (14), and is associated with poor prognosis in esophageal cancer (15). The present study identified that the positive expression rate of RNF2 in ESCC was $89.2 \%$, and that localization of this protein to the nucleus was consistent with

$\mathrm{A}_{\mathrm{a}}$

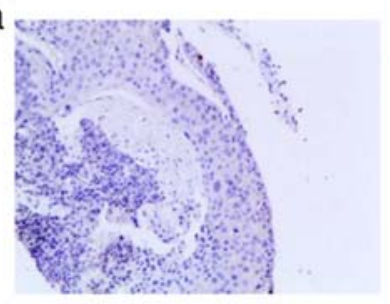

$\mathrm{b}$

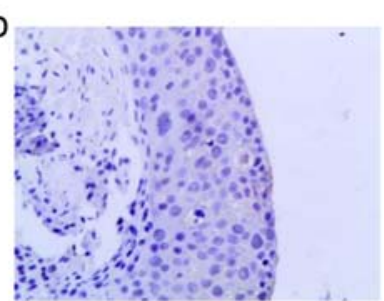

$\mathrm{Ba}$
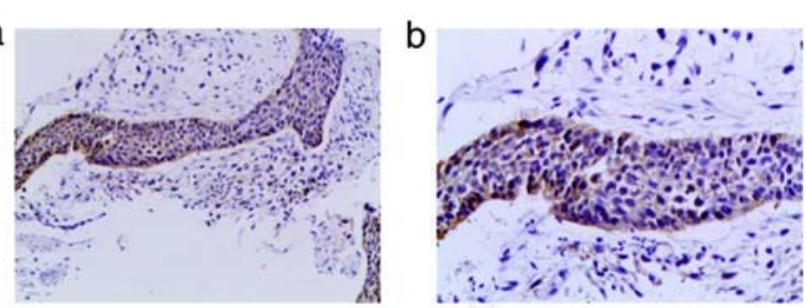

$\mathrm{Ca}$
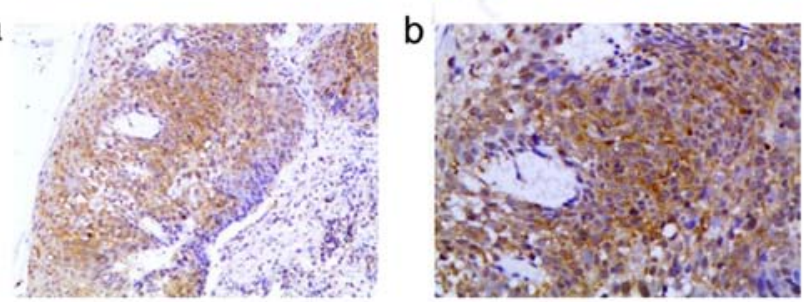

$\mathrm{Da}$
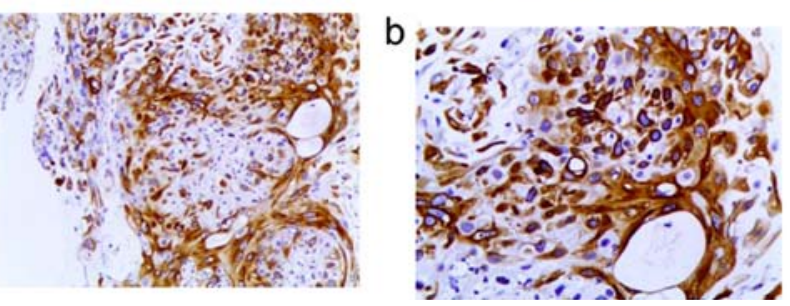

Figure 2. Expression levels of P-AKT protein in ESCC tissues. (A) No P-AKT expression in ESCC tissue; (a) magnification, $x 100$ and (b) magnification, $x 200$. (B) Weak expression of P-AKT in ESCC tissues: (a) magnification, $\mathrm{x} 100$ and (b) magnification, x200. (C) Moderate expression of P-AKT in ESCC tissues; (a) magnification, $x 100$ and (b) magnification, $x 200$. (D) Strong expression of P-AKT in ESCC tissues; (a) magnification, x100 and (b) magnification, $\mathrm{x} 200$. P-AKT, phosphor-protein kinase B; ESCC, esophageal squamous cell carcinoma.

previously published work (20). The upregulation of RNF2 expression in other tumors has also been associated with tumor size, pathological grade and poor patient prognosis (21). In the present study, a high RNF2 expression level was associated with tumor volume, prompting the hypothesis that, in ESCC, RNF2 serves an important role in early metastasis and tumor formation; this has also been confirmed by other studies (22-24).

The PI3K signaling pathway is involved in numerous cellular activities and sensitivity to radiotherapy, in addition to tumor metastasis and apoptosis (25-27). The phosphorylation of AKT to P-AKT is central to the PI3K pathway, and its activation stimulates the proliferation of tumor cells (28). Yoshioka et al (29) reported that the prognosis of a low P-AKT-expression group of patients with ESCC treated with chemotherapy had improved prognoses compared with those exhibiting high P-AKT expression levels. In addition, Schmitz et al (30) revealed a negative correlation between the P-AKT expression level and patient survival. However, the results of the present study revealed no significant differences 
Table III. Association between phosphor-protein kinase B expression and the clinicopathological variables of patients with esophageal squamous cell carcinoma.

\begin{tabular}{|c|c|c|c|c|c|c|c|c|c|}
\hline \multirow[b]{2}{*}{ Variables } & \multicolumn{8}{|c|}{ P-AKT expression } & \multirow[b]{2}{*}{ P-value } \\
\hline & $\begin{array}{c}(-) \\
(n=29)\end{array}$ & $\%$ & $\begin{array}{c}(+) \\
(n=39)\end{array}$ & $\%$ & $\begin{array}{c}(++) \\
(n=16)\end{array}$ & $\%$ & $\begin{array}{l}(+++) \\
(\mathrm{n}=1)\end{array}$ & $\%$ & \\
\hline \multicolumn{10}{|l|}{ Sex } \\
\hline Male & 13 & 44.8 & 28 & 71.8 & 11 & 68.8 & 1 & 100.0 & \multirow[t]{2}{*}{0.041} \\
\hline Female & 16 & 55.2 & 11 & 28.2 & 5 & 31.3 & 0 & 0.0 & \\
\hline \multicolumn{10}{|l|}{ Age, years } \\
\hline$\leq 66$ & 14 & 48.3 & 21 & 53.8 & 9 & 56.3 & 1 & 100.0 & \multirow[t]{2}{*}{0.456} \\
\hline$>66$ & 15 & 51.7 & 18 & 46.2 & 7 & 43.8 & 0 & 0.0 & \\
\hline \multicolumn{10}{|l|}{ Tumor location } \\
\hline Cervical & 1 & 3.4 & 3 & 7.7 & 2 & 12.5 & 0 & 0.0 & \multirow[t]{4}{*}{0.248} \\
\hline Upper thoracic & 6 & 20.7 & 13 & 33.3 & 6 & 37.5 & 0 & 0.0 & \\
\hline Middle thoracic & 15 & 51.7 & 18 & 46.2 & 5 & 31.3 & 0 & 0.0 & \\
\hline Lower thoracic & 7 & 24.1 & 5 & 12.8 & 3 & 18.8 & 1 & 100.0 & \\
\hline \multicolumn{10}{|l|}{ Tumor length, cm } \\
\hline$\leq 5$ & 10 & 34.5 & 19 & 48.7 & 7 & 43.8 & 1 & 100.0 & \multirow[t]{2}{*}{0.281} \\
\hline$>5$ & 19 & 65.5 & 20 & 51.3 & 9 & 56.3 & 0 & 0.0 & \\
\hline \multicolumn{10}{|l|}{ Tumor volume, $\mathrm{cm}^{3}$} \\
\hline$\leq 25$ & 8 & 27.6 & 12 & 30.8 & 6 & 37.5 & 0 & 0.0 & \multirow[t]{2}{*}{0.611} \\
\hline$>25$ & 21 & 72.4 & 27 & 69.2 & 10 & 62.5 & 1 & 100.0 & \\
\hline \multicolumn{10}{|l|}{ T stage } \\
\hline $1+2$ & 14 & 48.3 & 22 & 56.4 & 3 & 18.7 & 0 & 0.0 & \multirow[t]{2}{*}{0.117} \\
\hline $3+4$ & 15 & 51.7 & 17 & 43.6 & 13 & 81.3 & 1 & 100.0 & \\
\hline \multicolumn{10}{|l|}{$\mathrm{N}$ stage } \\
\hline 0 & 12 & 41.4 & 19 & 48.7 & 4 & 25.0 & 0 & 0.0 & \multirow[t]{2}{*}{0.309} \\
\hline 1 & 17 & 58.6 & 20 & 51.3 & 12 & 75.0 & 1 & 100.0 & \\
\hline \multirow{2}{*}{\multicolumn{10}{|c|}{$\begin{array}{l}\text { Tumor-Node- } \\
\text { Metastasis stage (17) }\end{array}$}} \\
\hline & & & & & & & & & \multirow{3}{*}{0.688} \\
\hline $\mathrm{I}+\mathrm{II}$ & 11 & 37.9 & 25 & 64.1 & 6 & 37.5 & 0 & 0 & \\
\hline III+IV & 18 & 62.1 & 14 & 35.9 & 10 & 62.5 & 1 & 100.0 & \\
\hline
\end{tabular}

P-AKT, phosphor-protein kinase B.

Table IV. Association between RNF2+P-AKT expression and the clinicopathological variables of patients with esophageal squamous cell carcinoma.

\begin{tabular}{|c|c|c|c|c|c|}
\hline \multirow[b]{3}{*}{ Variables } & \multicolumn{4}{|c|}{ RNF2/P-AKT expression } & \multirow[b]{3}{*}{ P-value } \\
\hline & \multicolumn{2}{|c|}{$\begin{array}{l}\mathrm{RNF} 2 / \mathrm{P}-\mathrm{AKT} \\
\text { both positive }\end{array}$} & \multicolumn{2}{|c|}{ Other } & \\
\hline & $(n=50)$ & $\%$ & $(n=30)$ & $\%$ & \\
\hline \multicolumn{6}{|l|}{ Sex } \\
\hline Male & 37 & 74.00 & 12 & 40.00 & 0.003 \\
\hline Female & 13 & 26.00 & 18 & 60.00 & \\
\hline \multicolumn{6}{|l|}{ T stage } \\
\hline 1 & 0 & 0.00 & 2 & 6.67 & 0.065 \\
\hline 2 & 17 & 34.00 & 8 & 26.67 & \\
\hline 3 & 6 & 12.00 & 8 & 26.67 & \\
\hline 4 & 27 & 54.00 & 12 & 40.00 & \\
\hline
\end{tabular}

RNF2, Ring finger protein 2; P-AKT, phosphor-protein kinase B; Other, including patients with RNF2/P-AKT both negative, RNF2$-\mathrm{P}-\mathrm{AKT}^{+-+++}$and RNF2 ${ }^{+-++}-\mathrm{P}-\mathrm{AKT}$. between the survival rates of the P-AKT-positive and -negative expression groups, which may result from differences in clinical data and treatment methods between the 2 groups. The small sample size, particularly the P-AKT ${ }^{(+++)}$number, was another factor that may have affected the results; however, to a certain extent, the bias caused by small sample size could be decreased by the analysis of $\mathrm{P}-\mathrm{AKT}^{(+-++)}$expression. A larger sample size may clarify this.

BMI1 is an important predictor of tumor progression (13) that is able to promote cellular activity, induce resistance to apoptosis, and increase the likelihood of metastasis (14). It may also be associated with treatment failure in a number of malignancies, including breast and prostate cancer, and hepatocellular carcinoma (31-33). Previous studies have demonstrated that the overexpression of BMI1 and RNF2 was associated with tumorcell transformation in multiple types of tumor tissue $(12,34)$. BMI1 is also essential for the ubiquitination of histone H2AX (35); when BMI1 is present, the capacity of RNF2 to ubiquitinate $\mathrm{H} 2 \mathrm{AX}$ is enhanced (36), while $\mathrm{H} 2 \mathrm{AX}$ itself is associated with the radiotherapeutic sensitivity of esophageal cancer cells (37). RNF2 serves as an E3 ubiquitin ligase $(35,38,39)$; BMI1 is 
Table V. Survival rates of patients with esophageal squamous cell carcinoma with different RNF2+P-AKT expression levels.

\begin{tabular}{|c|c|c|c|c|c|c|c|c|c|c|}
\hline \multirow[b]{2}{*}{ Expression levels } & \multicolumn{3}{|c|}{ Overall survival (\%) } & \multirow[b]{2}{*}{$\chi^{2}$} & \multirow[b]{2}{*}{$\mathrm{P}$-value } & \multicolumn{3}{|c|}{ Progression-free survival (\%) } & \multirow[b]{2}{*}{$\chi^{2}$} & \multirow[b]{2}{*}{ P-value } \\
\hline & 1-year & 3-year & 5-year & & & 1-year & 3-year & 5 -year & & \\
\hline \multicolumn{11}{|l|}{ RNF2 expression } \\
\hline Negative & 77.8 & 55.6 & 55.6 & 2.244 & 0.134 & 66.7 & 33.3 & 33.3 & 0.818 & 0.366 \\
\hline Positive & 75.7 & 37.8 & 21.6 & & & 62.2 & 25.7 & 15.5 & & \\
\hline \multicolumn{11}{|l|}{ P-AKT expression } \\
\hline Negative & 82.8 & 48.3 & 24.7 & 0.526 & 0.468 & 69.0 & 27.6 & 11.0 & 0.306 & 0.580 \\
\hline Positive & 69.6 & 32.1 & 17.1 & & & 55.4 & 25.0 & 20.6 & & \\
\hline \multicolumn{11}{|c|}{ RNF2/P-AKT expression } \\
\hline Positive & 68.0 & 28.0 & 20.0 & 4.205 & 0.040 & 52.0 & 20.0 & 14.4 & 3.407 & 0.065 \\
\hline Other & 86.7 & 53.3 & 31.1 & & & 76.7 & 33.3 & 18.3 & & \\
\hline
\end{tabular}

RNF2, Ring finger protein 2; P-AKT, phosphor-protein kinase B; Other, including patients with RNF2-negative/P-AKT-negative, RNF2-positive/P-AKT-negative and RNF2-negative/P-AKT-positive.
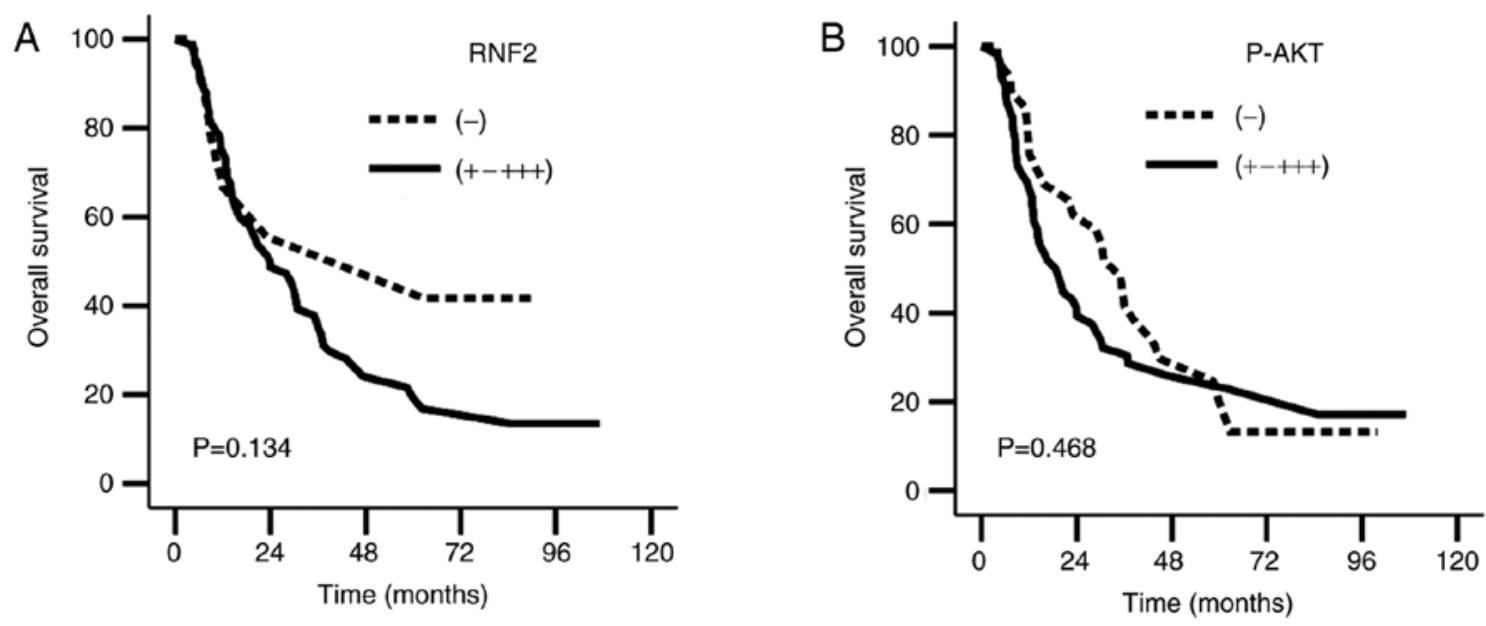

Figure 3. Overall survival curve of patients with esophageal squamous cell carcinoma with RNF2+P-AKT expression. (A) Overall survival curves of the $\mathrm{RNF}^{-}$vs. the RNF2 ${ }^{++++}$groups. (B) Overall survival curves of the P-AKT vs. the P-AKT ${ }^{++++}$groups. RNF2, Ring finger protein 2; P-AKT, phosphor-protein kinase B.

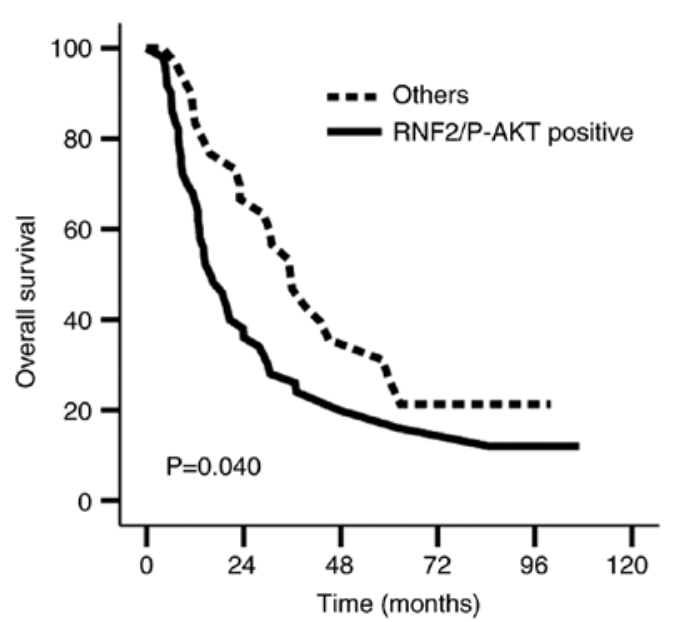

Figure 4. Overall survival curve of patients with esophageal squamous cell carcinoma in the RNF2+P-AKTpositive expression group compared with other group. RNF2, Ring finger protein 2; P-AKT, phosphor-protein kinase B; Other, including patients with RNF2-negative/P-AKT-negative, RNF2-positive/P-AKT-negative, RNF2-negative/P-AKT-positive. essential for the activity of this E3 ubiquitin ligase in the PRC1 complex (40), and the ubiquitination activity of RNF2 requires that BMI1 be present. In a previous study, it was revealed that the knockdown of BMI1 resulted in a DNA-damage response defect, and that the PI3K/AKT pathway could be perturbed to increase sensitivity to radiotherapy (16). Therefore, it was hypothesized that RNF2 overexpression may increase radiotherapeutic resistance by activating the PI3K/AKT pathway. IHC analysis was conducted using tissue samples from patients with ESCC, which revealed that the survival rate of those in the RNF2+P-AKT-positive expression group was significantly lower compared with that of the other group. In addition, multivariate analysis revealed that RNF2+P-AKT-positive expression was an independent prognostic factor affecting survival. To a degree, these results reflected the synergistic effects of RNF2 and P-AKT in ESCC. Therefore, it was hypothesized that the expression of RNF2 and P-AKT ESCC was an important prognostic indicator, though the association between these proteins requires further experimental confirmation. 
There were several limitations associated with the present study. Firstly, it was a single-center retrospective study with a small number of cases, and the results require additional confirmation from a larger prospective sample study. Secondly, the tissue samples were all from biopsy specimens, and therefore the tissues were small and not sufficient to fully evaluate the grading of ESCC. Therefore, the association between the degree of RNF2 and P-AKT expression, and the classification of tumor tissues, was not analyzed. Finally, the association between RNF2 and $\mathrm{P}-\mathrm{AKT}$ was not assessed in molecular in vitro studies, which would strengthen the conclusions drawn from the present study.

In conclusion, the present study revealed that the RNF2 and P-AKT proteins may be important oncogenes in the prognosis of patients with ESCC, and that their expression was associated with tumor volume and OS rate, indicating their use as important molecular markers of ESCC. Therefore, RNF2 and $\mathrm{P}-\mathrm{AKT}$ are predicted to be novel prognostic indicators for radical radiotherapy in patients with ESCC.

\section{Acknowledgements}

Not applicable.

\section{Funding}

No funding was received.

\section{Availability of data and materials}

The datasets generated and/or analyzed during the present study are available from the corresponding author on reasonable request.

\section{Authors' contributions}

QL, SZ and XY analyzed and interpreted the patient data regarding the research. QL, SZ and CS made substantial contributions to conception and design. QL and CS drafted the manuscript. QL, SL and CS were major contributors in writing the manuscript. SL and XZ performed the histological examination of the esophagus. All authors read and approved the final manuscript.

\section{Ethics approval and consent to participate}

All patients provided written informed consent to participate prior to the collection of tissue specimens and radiotherapy and/or chemotherapy. The present study was approved by the Medical Ethics Committee of the Clinical Research of the Fourth Affiliated Hebei Medical University.

\section{Patient consent for publication}

Not applicable.

\section{Competing interests}

The authors declare that they have no competing interests. 


\section{References}

1. Global Burden of Disease Cancer Collaboration; Fitzmaurice C, Dicker D, Pain A, Hamavid H, Moradi-Lakeh M, Maclntyre MF, Allen C, Hansen G, Woodbrook R, et al: The global burden of cancer 2013. JAMA Oncol 1: 505-527, 2015.

2. Pennathur A, Gibson MK, Jobe BA and Luketich JD: Oesophageal carcinoma. Lancet 381:400-412, 2013.

3. Siegel RL, Miller KD and Jemal A: Cancer Statistics. 2017. CA Cancer J Clin 67: 7-30, 2017.

4. Otte AP and Kwaks TH: Gene repression by Polycomb group protein complexes: A distinct complex for every occasion? Curr Opin Genet Dev 13: 448-454, 2003.

5. Levine SS, Weiss A, Erdjument-Bromage H, Shao Z, Tempst P and Kingston RE: The core of the polycomb repressive complex is compositionally and functionally conserved in flies and humans. Mol Cell Biol 22: 6070-6078, 2002.

6. Kuzmichev A, Nishioka K, Erdjument-Bromage H, Tempst P and Reinberg D: Histone methyltransferase activity associated with a human multiprotein complex containing the Enhancer of Zeste protein. Genes Dev 16: 2893-2905, 2002.

7. Bentley ML, Corn JE, Dong KC, Phung Q, Cheung TK and Cochran AG: Recognition of UbcH5c and the nucleosome by the Bmi1/Ringlb ubiquitin ligase complex. EMBO J 30: 3285-3297, 2011.

8. Buchwald G, van der Stoop P, Weichenrieder O, Perrakis A van Lohuizen M and Sixma TK: Structure and E3-ligase activity of the Ring-Ring complex of polycomb proteins Bmil and Ring1b. EMBO J 25: 2465-2474, 2006.

9. Li Z, Cao R, Wang M, Myers MP, Zhang Y and Xu RM: Structure of a Bmi-1-Ring1B polycomb group ubiquitin ligase complex. J Biol Chem 281: 20643-20649, 2006.

10. Ruan ZP, Xu R, Lv Y, Tian T, Wang WJ, Guo H and Nan KJ: Bmil knockdown inhibits hepatocarcinogenesis. Int J Oncol 42: 261-268, 2013.

11. Song W, Tao K, Li H, Jin C, Song Z, Li J, Shi H, Li X, Dang Z and Dou K: Bmi-1 is related to proliferation, survival and poor prognosis in pancreatic cancer. Cancer Sci 101: 1754-1760, 2010

12. Sánchez-Beato M, Sánchez E, González-Carreró J, Morente M, Díez A, Sánchez-Verde L, Martín MC, Cigudosa JC, Vidal M and Piris MA: Variability in the expression of polycomb proteins in different normal and tumoral tissues. A pilot study using tissue microarrays. Mod Pathol 19: 684-694, 2006.

13. Bosch A, Panoutsopoulou K, Corominas JM, Gimeno R, Moreno-Bueno G, Martín-Caballero J, Morales S, Lobato T, Martínez-Romero C, Farias EF, et al: The Polycomb group protein RING1B is overexpressed in ductal breast carcinoma and is required to sustain FAK steady state levels in breast cancer epithelial cells. Oncotarget 5: 2065-2076, 2014.

14. Su WJ, Fang JS, Cheng F, Liu C, Zhou F and Zhang J: RNF2/ Ring1b negatively regulates p53 expression in selective cancer cell types to promote tumor development. Proc Natl Acad Sci USA 110: 1720-1725, 2013.

15. Yang XX, Ma M, Sang MX, Wang XX, Song H, Liu ZK and Zhu SC: Radiosensitization of esophageal carcinoma cells by knockdown of RNF2 expression. Int J Oncol 48: 1985-1996, 2016

16. Yang XX, Ma M, Sang MX, Zhang XY, Liu ZK, Song H and Zhu SC: BMI-1 suppression increases the radiosensitivity of oesophageal carcinoma via the PI3K/Akt signaling pathway. Oncol Rep 39: 667-678, 2018.

17. Edge SB, Byrd DR, Compton CC, Fritz AG, Greene FL and Trotti A (eds.): AJCC Cancer Staging Mamal. 7th edition. Springer-Verlag, New York, NY, pp103-15, 2009.

18. Masunaga R, Kohno H, Dhar DK, Ohno S, Shibakita M, Kinugasa S, Yoshimura $\mathrm{H}$, Tachibana $\mathrm{M}$, Kubota $\mathrm{H}$ and Nagasue N: Cyclooxygenase-2 expression correlates with tumor neovascularization and prognosis in human colorectal carcinoma patients. Clin Cancer Res 6: 4064-4068, 2000.

19. Wu D, Ding Y, Wang S, Zhang Q and Liu L: Increased expression of high mobility group box 1 (HMGB1) is associated with progression and poor prognosis in human nasopharyngeal carcinoma. J Pathol 216: 167-175, 2008.

20. Chen J, Xu H, Zou X, Wang J, Zhu Y, Chen H, Shen B, Deng X, Zhou A, Chin YE, et al: Snail recruits Ring1B to mediate transcriptional repression and cell migration in pancreatic cancer cells. Cancer Res 74: 4353-4363, 2014.

21. Chen S, Chen J, Zhan Q, Zhu Y, Chen H, Deng X, Hou Z, Shen B, Chen Y and Peng C: H2AK119Ub1 and H3K27Me3 in molecular staging for survival prediction of patients with pancreatic ductal adenocarcinoma. Oncotarget 5: 10421-10433, 2014.
22. Rai K, Akdemir KC, Kwong LN, Fiziev P, Wu CJ, Keung EZ, Sharma S, Samant NS, Williams M, Axelrad JB, et al: Dual Roles of RNF2 in melanoma progression. Cancer Discov 5: 1314-1327, 2015.

23. van der Stoop P, Boutsma EA, Hulsman D, Noback S, Heimerikx M, Kerkhoven RM, Voncken JW, Wessels LF and van Lohuizen M: Ubiquitin E3 ligase Ring1b/Rnf2 of polycomb repressive complex 1 contributes to stable maintenance of mouse embryonic stem cells. PLoS One 3: e2235, 2008.

24. van der Velden YU, Wang L, Querol Cano L and Haramis AP The polycomb group protein ring $1 \mathrm{~b} / \mathrm{rnf} 2$ is specifically required for craniofacial development. PLoS One 8: e73997, 2013.

25. Zhang XJ, Yu HY, Cai YJ and Ke M: Lycium barbarum polysaccharides inhibit proliferation and migration of bladder cancer cell lines BIU87 by suppressing Pi3K/AKT pathway. Oncotarget 8: 5936-5942, 2017.

26. Bussink J, van der Kogel AJ and Kaanders JH: Activation of the PI3-K/AKT pathway and implications for radioresistance mechanisms in head and neck cancer. Lancet Oncol 9: 288-296, 2008.

27. Deng R, Tang J, Ma JG, Chen SP, Xia LP, Zhou WJ, Li DD, Feng GK, Zeng YX and Zhu XF: PKB/Akt promotes DSB repair in cancer cells through upregulating Mre11 expression following ionizing radiation. Oncogene 30: 944-955, 2011.

28. Zhang Y, Zheng L, Ding Y, Li Q, Wang R, Liu T, Sun Q, Yang H, Peng S, Wang W and Chen L: MiR-20a induces cell radioresistance by activating the PTEN/PI3K/Akt signaling pathway in hepatocellular carcinoma. Int J Radiat Oncol Biol Phys 92: 1132-1140, 2015.

29. Yoshioka A, Miyata H, Doki Y, Yasuda T, Yamasaki M, Motoori M, Okada K, Matsuyama J, Makari Y, Sohma I, et al: The activation of Akt during preoperative chemotherapy for esophageal cancer correlates with poor prognosis. Oncol Rep 19: 1099-1107, 2008.

30. Schmitz KJ, Otterbach F, Callies R, Levkau B, Hölscher M, Hoffmann O, Grabellus F, Kimmig R, Schmid KW and Baba HA: Prognostic relevance of activated Akt kinase in node-negative breast cancer: A clinicopathological study of 99 cases. Mod Pathol 17: 15-21, 2004.

31. Wang L, Liu JL, Yu L, Liu XX, Wu HM, Lei FY, Wu S and Wang X: Downregulated miR-495 [Corrected] inhibits the G1-S Phase transition by targeting Bmi-1 in breast cancer. Medicine (Baltimore) 94: e718, 2015

32. Jin M, Zhang T, Liu C, Badeaux MA, Liu B, Liu R, Jeter C, Chen X, Vlassov AV and Tang DG: miRNA-128 suppresses prostate cancer by inhibiting BMI-1 to inhibit tumor-initiating cells. Cancer Res 74: 4183-4195, 2014

33. Yang F, Lv LZ, Cai QC and Jiang Y: Potential roles of EZH2, Bmi-1 and miR-203 in cell proliferation and invasion in hepatocellular carcinoma cell line Hep3B. World J Gastroenterol 21: 13268-13276, 2015.

34. Richly H, Aloia L and Di Croce L: Roles of the Polycomb group proteins in stem cells and cancer. Cell Death Dis 2: e204, 2011.

35. Wang H, Wang L, Erdjument-Bromage H, Vidal M, Tempst P, Jones RS and Zhang Y: Role of histone H2A ubiquitination in Polycomb silencing. Nature 431: 873-878, 2004.

36. Rao PS, Satelli A, Zhang S, Srivastava SK, Srivenugopal KS and Rao US: RNF2 is the target for phosphorylation by the p38 MAPK and ERK signaling pathways. Proteomics 9: 2776-2787, 2009.

37. Shi HY and Zhu SC: Radiosensitization of esophageal cancer cells ECA109 by knockdown of H2AX. Thorac Cancer 4: 254-263, 2013

38. Ohtsubo M, Yasunaga S, Ohno Y, Tsumura M, Okada S, Ishikawa N, Shirao K, Kikuchi A, Nishitani H, Kobayashi M and Takihara Y: Polycomb-group complex 1 acts as an E3 ubiquitin ligase for Geminin to sustain hematopoietic stem cell activity. Proc Natl Acad Sci USA 105: 10396-10401, 2008.

39. Sen N, Satija YK and Das S: PGC-1 $\alpha$, a key modulator of p53, promotes cell survival upon metabolic stress. Mol Cell 44: 621-634, 2011.

40. Ben-Saadon R, Zaaroor D, Ziv T and Ciechanover A: The polycomb protein Ring1B generates self atypical mixed ubiquitin chains required for its in vitro histone $\mathrm{H} 2 \mathrm{~A}$ ligase activity. Mol Cell 24: 701-711, 2006.

This work is licensed under a Creative Commons Attribution-NonCommercial-NoDerivatives 4.0 International (CC BY-NC-ND 4.0) License. 